\title{
ALGUNS APONTAMENTOS PARA UMA CRÍTICA DA EDUCAÇÃO A DISTÂNCIA (EaD) NA EDUCAÇÃO BRASILEIRA EM TEMPOS DE PANDEMIA
}

\author{
Some notes for a critique of e-learning (EaD) in Brazilian Education \\ in times of pandemic
}

\author{
Astrogildo Luiz de França Filho \\ Professor Assistente do DGEO/FFP/UERJ \\ astrogildo.franca@uerj.br \\ Charlles da França Antunes \\ Professor Associado do DGEO/FFP/UERJ \\ charllesdafranca@gmail.com \\ Marcos Antônio Campos Couto \\ Professor Associado do DGEO/FFP/UERJ \\ professormarcoscouto@gmail.com
}

Artigo enviado para publicação em 30/04/2020 e aceito em 04/05/2020

DOI: $10.12957 /$ tamoios.2020.50535

\section{Resumo}

Em meio à atual crise do sistema capitalista, agora agravada pela crise sanitária mundial trazida à tona pela pandemia da Covid-19, um dos impactos gerados no âmbito educacional é o aumento vertiginoso da pressão no setor público e privado pela implantação da $\mathrm{EaD}$ em praticamente todos os níveis da educação básica e superior. $\mathrm{O}$ objetivo deste texto é apresentar um quadro básico que articule três elementos fundamentais deste processo. A forma com que o Estado brasileiro vem organizando seu Sistema Nacional de Educação, a articulação desse Estado com o setor empresarial da educação privada e, ao final, alguns elementos que permitam situar a crítica a esta modalidade da educação como ponto de partida para pensar uma educação realmente necessária.

Palavras-chave: EaD, tecnologia, Todos pela Educação, Sistema Nacional de Educação

\begin{abstract}
In the midst of the current crisis of the capitalist system, now worsened by the global health crisis brought about by the Covid-19 pandemic, one of the impacts generated in the educational field is the dizzying increase in pressure in the public and private sector for the implementation of distance education in practically all basic and higher education levels. The purpose of this text is to present a basic framework that articulates three fundamental elements of this process. The way in which the Brazilian State has been organizing its National Education System, the articulation of that State with the business sector of private education and, in the end, some elements that make it possible to situate the criticism to this modality of education as a starting point for thinking about a really needed education.
\end{abstract}

Keywords: E-learning (EaD), technology, All for Education, National Education System 


\section{Introdução}

Desde a segunda quinzena do mês de março, com as políticas de isolamento social de combate ao contágio do coronavírus (SARS-CoV-2), o Brasil especialmente vive as imposições de uma situação que, independente do grau de envolvimento e comprometimento do Executivo Federal, mudou de forma drástica o cotidiano da população, e que ainda carrega um conjunto de transformações não tão perceptíveis. Ao mesmo tempo, possibilitou a identificação de uma série de processos já em largo estágio de avanço nos mais diversos setores, da pauta macroeconômica à social ou ambiental, que por sua vez, se desdobram em uma série de pontos tão diversificados que é quase impossível sintetizá-los em um quadro amplo de análise.

No que diz respeito à pauta específica da educação, a manifestação mais sensível dos impactos do coronavírus no Brasil se observa na pressão encontrada em todos os entes federativos e em todas as etapas da educação básica e superior pela implantação massiva do que se convencionou chamar de Educação à Distância $(\mathrm{EaD})$. Entretanto, isto deve ser interpretado como etapa posterior de um processo cuja gênese é anterior ao surgimento da COVID-19 e, com consequências, tende a se desdobrar após este período mais intenso de propagação da pandemia.

Para contribuir na montagem de sínteses críticas desse processo, o artigo objetiva analisar a relação entre o atual momento de isolamento social em função da pandemia e as tendências já em curso nas políticas educacionais brasileiras relativas à $\mathrm{EaD}$, a partir da perspectiva de seus diferentes sujeitos; entre os quais muitos veem a situação como momento de oportunidades.

A metodologia de análise distingue e articula três elementos julgados centrais para a compreensão do que significa o uso do EaD neste momento específico do país e, a partir deles, algumas possíveis direções deste processo. O primeiro deles está relacionado à forma como o Estado brasileiro, ao longo dos últimos 20 anos, pelo menos, estruturou seu próprio Sistema Nacional de Educação, ou seja, como de forma gradativa, optou-se por um modelo de organização das relações entre a União, os estados e os municípios de forma centralizada em torno do primeiro; em que o Governo Federal assumiu a primazia dos processos decisórios na política educacional, em especial as avaliações nacionais, a Base Nacional Comum Curricular (BNCC), a avaliação e seleção de materiais e livros didáticos (Programa Nacional do Livro Didático - PNLD) e as diretrizes curriculares para 
a formação de professores; restando, em contrapartida, aos outros entes federativos (estados e municípios), a execução das normativas.

O segundo elemento indica como esta estrutura estatal centralizada é permeada por uma lógica mercantilista, no que concerne não apenas à função do Estado de garantir o acesso a educação para toda população, mas no diálogo cada vez mais estreito em que essa função é planejada com grandes grupos empresariais que buscam assumir a função gestora desse mesmo Estado, como o caso da organização Todos pela Educação (TPE).

Como resultado, chegamos ao terceiro elemento: a capilarização progressiva no âmbito das universidades e de comunidade acadêmica do consenso da legitimidade da $\mathrm{EaD}$ enquanto modalidade de educação a ser utilizada como instrumento de formação pedagógica, sobretudo no ensino superior, inclusive o público.

Por fim, além da questão política que envolve a $\mathrm{EaD}$, há forte questão teórica na medida que se desenvolve certo consenso mesmo entre educadores supostamente do campo mais progressista e que necessita ser também destrinchado para ser enfrentado.

$\mathrm{O}$ artigo segue a sequência dos três temas centrais propostos.

\section{A avaliação da educação brasileira: a busca por resultados}

Duas atribuições da União permitem enfatizar aspectos relevantes das atuais políticas educacionais. De acordo com artigo nono da LDB 9.394/1996 a União incumbirse-á de estabelecer, em colaboração com os estados, o Distrito Federal e os municípios, competências e diretrizes para a educação infantil, o ensino fundamental e o ensino médio, que nortearão os currículos e seus conteúdos mínimos, de modo a assegurar formação básica comum (inciso IV) e assegurar processo nacional de avaliação do rendimento escolar no ensino fundamental, médio e superior, em colaboração com os sistemas de ensino, objetivando a definição de prioridades e a melhoria da qualidade do ensino (inciso VI); entre outras funções. Avaliar o desempenho dos estudantes (e não o rendimento escolar ${ }^{1}$ ) pela aplicação de testes em larga escala e, através dos seus resultados, estabelecer metas, diretrizes e referenciais curriculares, tornaram-se peçaschave da educação brasileira. Prova Brasil ${ }^{2}$ (e provas regionais, tipo SAERJ no Rio de Janeiro), Exame Nacional do Ensino Médio (ENEM) e Exame Nacional de Desempenho dos Estudantes (ENADE), por um lado, e Base Nacional Comum Curricular (BNCC), por outro. 
Esta LDB foi aprovada no primeiro governo FHC (1995-1998), em um contexto bem diferente do momento da elaboração da CF de 1988. Já se desenvolvia no Brasil as medidas da economia política neoliberal de reforma do Estado - que se desdobram até hoje - no contexto internacional da reestruturação produtiva do fordismo à acumulação flexível - com suas graves consequências para a precarização das condições de trabalho e do clima cultural da pós-modernidade (Harvey, 1993; Moreira, 2016).

A reforma do Estado - do modelo keynesiano do Bem Estar Social para o neoliberal - foi pautada por certo receituário - do tipo Consenso de Washington - com medidas de privatização de empresas e serviços públicos, equilíbrio fiscal, abertura da economia nacional pela desregulação dos mercados; tudo isso na perspectiva do Estado mínimo (para os trabalhadores) e forte na capacidade de controle e, inspirado nas ideias de administração gerencial, na execução de políticas sociais como serviços - mas não exclusivos do Estado (público, mas não estatal).

Novo regime de acumulação e de regulamentação política e social, a acumulação flexível, segundo Harvey (1993), significa:

...um confronto direto com a rigidez do fordismo. Ela se apoia na flexibilidade dos processos de trabalho, dos mercados de trabalho, dos produtos e padrões de consumo. Caracteriza-se pelo surgimento de setores de produção inteiramente novos, novas maneiras de fornecimento de serviços financeiros, novos mercados e, sobretudo, taxas altamente intensificadas de inovação comercial, tecnológica e organizacional. A acumulação flexível envolve rápidas mudanças dos padrões do desenvolvimento desigual, tanto entre setores como entre regiões geográficas, criando, por exemplo, um vasto movimento no emprego no chamado "setor de serviços", bem como conjuntos industriais completamente novos em regiões até então subdesenvolvidas.... Ela também envolve um novo movimento que chamarei de "compressão do espaço-tempo" no mundo capitalista - os horizontes temporais da tomada de decisões privada e pública se estreitaram, enquanto a comunicação via satélite e a queda dos custos do transporte possibilitaram cada vez mais a difusão imediata dessas decisões num espaço cada vez mais amplo e variegado.

Esses poderes aumentados de flexibilidade e mobilidade permitem que os empregadores exerçam pressões mais fortes de controle do trabalho sobre uma força de trabalho de qualquer maneira enfraquecida por dois surtos selvagens de deflação, força que viu o desemprego aumentar nos países capitalistas avançados... para níveis sem precedentes no pós-guerra. O trabalho organizado foi solapado pela reconstrução de focos de acumulação flexível em regiões que careciam de tradições industriais anteriores e pela reimportação para os centros mais antigos das normas e práticas regressivas estabelecidas nessas novas áreas. A acumulação flexível parece implicar níveis relativamente altos de desemprego "estrutural"..., rápida destruição e reconstrução de habilidades, ganhos modestos (quando há) de salários reais... e o retrocesso do poder sindical - uma das colunas políticas do regime fordista. (Harvey, 1993, p. 140141).

Bases para o regime de acumulação rentista, que se seguirá, a acumulação flexível está baseada na forte inovação tecnológica, em novas funções dos serviços financeiros, 
em indícios do retorno hegemônico da esfera da circulação pelo vasto movimento do setor de serviços/consumo, e na flexibilidade do processo e do mercado de trabalho e dos padrões de consumo. Confrontado o movimento sindical, o desemprego estrutural conduz a novas formas de organização (precarização) do trabalho: múltiplas tarefas, pagamento pessoal por sistemas de bonificações, sem tarefas demarcadas, treinamento no trabalho, organização horizontal do trabalho, corresponsabilidade do trabalhador, segurança no emprego para os trabalhadores centrais e nenhuma segurança e condições dignas de trabalho para os trabalhadores terceirizados (Harvey, 1993, p. 167-168).

O pós-modernismo, proclamando o fim da totalidade, das verdades eternas e universais e dos grandes relatos mediante os quais todas as coisas podem ser conectadas, põe o foco no efêmero, no indeterminado e no fragmento. Com enormes consequências para a organização do conhecimento sistematizado, tanto na universidade quanto na escola, o pós-modernismo questiona a divisão dos domínios científicos da filosofia neokantiana e positivista, e propõe superar a fronteira que separa e isola os campos de conhecimento da filosofia, das ciências humanas e naturais.

Esta trilogia de reestruturações das instituições (pós-estatismo), da esfera econômico-social e das novas feições do mundo do trabalho (pós-fordismo) e do pensamento (pós-modernismo) vai compor o "rentismo como centro sistêmico da acumulação capitalista planetarizada" com seu "modelo de espaço concentradodesconcentrado, integrado-fragmentado, fixo-fluido com que vai instituir a forma polissêmica e diversificada de excedente, e assim de conflito e tensionamento" (Moreira, 2016, p. 107).

Dominando os serviços e o consumo de massa ou individualizado, o capital rentista, “arrumado numa relação reprodutiva de esquema diretamente D-D', o esquema do dinheiro puro, tem, porém, de nutrir-se no movimento da acumulação D-M-D”, através do "controle da esfera da realização do valor" (Moreira, 2016, p. 137). Herdeira, dependente e relativamente autonomizada da atividade industrial-financeiro, a acumulação rentista se vale da livre mobilidade territorial do dinheiro e se alimenta da especulação. Por outro lado, é fonte de crédito e financiamento do consumo das empresas, das fazendas, dos trabalhadores formais e informais, dos estudantes universitários, sujeitando o lucro, a renda e o salário ao pagamento de dívidas, financeirizando as relações sociais e a vida cotidiana. A base geográfico-espacial de apoio é o modo de vida urbano - a urbanização da humanidade -; concentração que viabiliza a aceleração dos processos. 
Como avaliar a nova relação entre sociedade, trabalho e educação em face de tais mudanças? À escola, agora, cabe formar para a cidadania (obediente e rebelde), para o trabalho flexível formal e precário (o empreendedor) e, atendendo as necessidades da acumulação rentista, para o consumo de massa (consumidores). As diretrizes curriculares e os resultados da educação brasileira serão auferidos em função das metas definidas por estas novas necessidades e configurações da acumulação capitalista.

\title{
A gestão empresarial da escola pública
}

O conjunto de medidas educacionais, de caráter eminentemente produtivista ou tecnicista, identificados pelo professor Luiz Carlos de Freitas na agenda neoliberal no Brasil, pode ser sintetizado pelo termo criado por Diane Ravitch (2011) com respeito à reforma educacional nos EUA: "reforma empresarial da educação" ou "gestão empresarial da educação pública"3. De caráter empresarial, o modelo a ser seguido pela educação pública é o modo de organização da iniciativa privada, da gestão empresarial dos negócios, empresas ou grandes empreendimentos, visando à obtenção do seu resultado pela diminuição dos custos e a mais alta lucratividade. A escola pública não se transforma em instituição privada, mas sua gestão é realizada pela lógica privada (ou mesmo por uma empresa privada). De acordo com Freitas (2012, p. 379), as "categorias centrais que definem esta política educacional envolvem uma combinação de responsabilização, meritocracia e privatização":

\begin{abstract}
Um sistema de responsabilização envolve três elementos: testes para os estudantes, divulgação pública do desempenho da escola e recompensas e sanções (Kane \& Staiger, 2002). As recompensas e sanções compõem o caráter meritocrático do sistema, mas não só, já que a própria divulgação pública dos resultados da escola constitui em si mesma uma exposição pública que envolve alguma recompensa ou sanção públicas. A meritocracia é uma categoria, portanto, que perpassa a responsabilização. (Freitas, 2012, p. 383)
\end{abstract}

A partir do resultado de testes padronizados aplicados em grande escala (não por amostragem), o desempenho da escola significa, para os gestores e professores, responsabilização, ônus (punições ${ }^{4}$ ) ou bônus (premiações). Para as famílias, a possibilidade de escolha, o que pode conduzir à lógica mercadológica de competição entre as escolas.

A gestão empresarial também implica no desenvolvimento da "indústria da educação", através de empresas que prestam serviços de avaliação (elaboração, aplicação 
e correção de provas), de consultoria, de gestão (de escolas) e de apostilamento de conteúdo aplicado aos alunos, ou da venda de pacotes tecnológicos educacionais, programas, materiais digitais, etc.

Nos EUA, tais políticas foram levadas a cabo por fundações privadas que influenciaram largamente programas de reformas educacionais em muitos estados e cidades. No Brasil, as fundações de direito privado estão agrupadas na organização Todos Pela Educação (TPE), que também abriga acadêmicos, think tanks, mídia, organizações internacionais, ongs, Estado e empresários.

Orientado por Diretrizes de organizações internacionais (Unesco, Banco Mundial, BIRD), o sistema educacional nacional deve se responsabilizar pela formação de mãode-obra capaz de aumentar a produtividade e competitividade, projetar o país internacionalmente e fixar investimentos estrangeiros (Martins, 2016, p. 22). De acordo com esta pesquisadora, os princípios pedagógicos do TPE estão pautados na pedagogia dos resultados e das competências, que garanta o aprendizado de conhecimentos instrumentais e de competências e habilidades de caráter adaptativo às exigências do sistema (Martins, 2016, p. 59), incluindo as competências socio emocionais ${ }^{5}$. Contudo, esta adaptação inclui a formação de consumidores no contexto do desemprego estrutural através da formação de empreendedores, trabalhadores informais - sem seguridade social - nas diferentes modalidades de geração de renda.

Fazem parte deste receituário educacional:

-Combinar relevância e meritocracia.

- Pensar além das disciplinas, por competências e habilidades.

- Reorganizar os conteúdos através de novos métodos.

-Financiamento público de estudantes em escolas particulares (vouchers).

-Instituições públicas geridas pela lógica ou por empresa privada (escolas charters).

- Diminuir a pressão pelo acesso ao ensino superior, considerando que não é o único caminho de inserção na sociedade e no mundo do trabalho.

- Cursos superiores do futuro serão híbridos de ensino presencial e à distância. 
Estas políticas - umas mais, outras menos - já estão em curso na educação brasileira nas esferas federal, estaduais e municipais, fortemente influenciadas pela atuação do Todos Pela Educação.

A crise da pandemia de covid-19 se torna uma janela de oportunidades para uso da tecnologia na educação neste âmbito de parceria público-privada, considerando a maleabilidade do Sistema Nacional de Educação aos interesses e ações desses novos sujeitos da educação pública brasileira.

\section{Criticar a EaD é criticar a tecnologia na educação?}

O novo patamar que o debate sobre o uso do $\mathrm{EaD}$ na educação básica alcançou, sobretudo na escola pública, chama a atenção pela necessidade de repensar a relação entre educação e tecnologia com uma interpretação por muitas vezes dúbia e confusa sobre o uso desta no processo educativo. Seguem alguns pontos julgados fundamentais para apoiar esta discussão em bases mais sólidas.

É curioso neste caso como a tecnologia é apresentada como algo que está sempre envolvida em uma espécie de "aura" de neutralidade, quando na verdade é necessário compreendê-la na conotação da qual já falava Álvaro Vieira Pinto quando tipificou a tecnologia também como uma ideologia:

\footnotetext{
A tecnologia também converte-se em teologia da máquina, à qual, imitando-se os casos clássicos de outras formas de alienação, o homem, o técnico ou o operário se aliena, faz votos próprios de devoção. Daí em diante desconhecerá ter transferido para ela, a título de valor transcendental o que era inerente à sua realidade pessoal. Esquece que a máquina não passa de obra sua, produto de suas finalidades interiores, realizado mediante as ideias que adquiriu, e acredita ao contrário dever deixar-se possuir pela tecnologia, porque só assim poderá adquirir um nome e uma essência humana, a de técnico. (...) A mística da tecnologia condensa uma das modalidades irracionais do idealismo contemporâneo. (PINTO, 2005, p. 291. Grifo nosso).
}

Dentro desta mística sobre a qual trata Pinto, parte-se do pressuposto que identifica a tecnologia como algo dotado de um existir externo ao ser humano, quando na verdade é sua própria criação, é um produto do seu trabalho. O uso da tecnologia na educação é incorporado por muitas vezes com um efeito mistificador que inverte a sua relação com o educando, inserindo-a como o próprio educador ${ }^{6}$. É como se a plataforma virtual em si, o material didático (supostamente personalizado), o canal de chat, o e-mail, as várias videoconferências ou lives que agora proliferam de forma abundante, a internet 
como um todo, por si só tivessem mesmo a capacidade de ensinar algo ou de educar, no sentido mais amplo e complexo que este termo carrega.

Ao pensar a técnica não podemos escapar de sua materialidade ou de sua natureza objectual ou funcional, pois restringir-nos a essa perspectiva nos colocaria na conclusão de que o uso que o indivíduo ou a sociedade fazem de determinada técnica já estaria previamente determinado pela natureza instrumental da mesma, numa clara inversão dos polos analíticos.

Ora, se à técnica não podemos atribuir intencionalidade em si-mesma, o mesmo não podemos estabelecer quanto ao uso. Portanto, se o uso que se projeta vem em resposta à demandas específicas e definidas, dos indivíduos e/ou da sociedade, esse já se faz prenhe de projeções, intenções, razões; assim, nesse momento não mais estaremos falando de técnica, e sim de um uso determinado da técnica, de um projeto técnico. (Mota, 2016, p.36)

Mesmo a sensação de conexão e interatividade dadas pelos aparatos técnicos atuais deveria também ser percebida como ideologia. Afinal de contas, será que o enorme crescimento das comunicações pessoais através de programas de videoconferência por si só permite que as necessidades afetivas, intelectuais e materiais sejam satisfeitas? Ou até quando a angústia gerada pela impossibilidade do encontro com os entes queridos será suportável apenas com o uso dessas ferramentas tecnológicas?

O meio técnico, pelo capitalismo, se funde e se assimila ao próprio espaço, e se apresenta como projeto, onde uma nova teleologia se propõe, na qual o valor relativo transmutado em técnica seria o meio e o fim da realização do ser social.

\begin{abstract}
"O meio técnico produtivo se apresenta, para muito além de sua instrumentalidade, como um artifício de poder, como uma estrutura de controle e organização das relações sociais, de maneira que estas não somente se exerçam como relações sociais de troca, mas, e principalmente, como relações técnicas e assim reafirmem a necessidade do meio técnico, sua implantação e expansão em todos os domínios da vida, incorporando a totalidade do horizonte socioespacial do capitalismo as regras do valor relativo. Técnica e espaço se fundem assim, no interior do capitalismo, ao processo de reprodução do valor. Respondem integralmente as suas formulações e orientações e se transfiguram em estruturas alienantes e subservientes ao controle social. Eis nosso tema e nossa motivação para apresentar a presente tese como esclarecimento ao „fetiche tecnológico “dos tempos atuais”. (Mota, 2016, p.14)
\end{abstract}

$\mathrm{Na}$ verdade, o pensamento mais perigoso posto por este fetichismo da tecnologia na educação é aquele que busca reduzir toda a complexidade da prática social pedagógica, aqui entendida no seu sentido mais totalizante, como um conjunto de procedimentos a serem cumpridos. Ou seja, um conjunto específico de ações passíveis de identificação, isolamento, catalogação e reorganização assim como se queira, a qualquer hora, em $\underline{\text { qualquer lugar e em qualquer situação, conformando assim um tipo particular de... }}$ 
técnica. Não à toa, Saviani (2008) dá o nome de neotecnicismo a esta tendência dentro da história das ideias pedagógicas.

É justamente a partir desta concepção da educação como uma simples técnica instrumentalizada que se pode considerar a sua capacidade de replicação, de reprodução. Aqui se esconde outro elemento importante: o discurso do ensino personalizado na EaD, como se o uso das mídias digitais e da internet permitisse também ampliar a capacidade de contato e solução para cada uma das situações reais de aprendizagem cotidianas de cada estudante.

Ora, como apontado recentemente por Freitas (2020), essas possibilidades geradas a partir das situações reais concretas de cada pessoa não são cabíveis, nem previsíveis em uma simples live, uma apostila, um vídeo pré-produzido ou mesmo em um algoritmo. Elas aparecem subitamente em qualquer momento da relação ensinoaprendizagem e é nesse contato direto com o professor que tais situações podem ser compreendidas, analisadas e solucionadas, ou seja, apenas a figura do professor é capaz de lidar com cada um destes casos e, assim, garantir uma relação "personalizada", de fato. Portanto, Freitas tem toda razão neste aspecto: ao contrário do que se defende, a EaD despersonaliza o ensino, massificando-o a partir de um conteúdo programático prévio e de uma metodologia prévia, justamente o oposto de que defendia Paulo Freire:

\footnotetext{
Por isto é que não podemos, a não ser ingenuamente, esperar resultados positivos de um programa, seja educativo num sentido mais técnico ou de ação política se, desrespeitando a particular visão de mundo que tenha ou esteja tendo o povo, se constitui numa espécie de 'invasão cultural', ainda que feita com a melhor das intenções. (FREIRE, 1987, p. 84)
}

Outro aspecto, mais situado no plano do empírico, portanto mais aparente dessa mística, é aquele já alertado por Milton Santos (1996, p. 219) sobre o problema da distribuição desigual das técnicas no mundo. Exatamente por constituir-se como uma extensão do trabalho, portanto condicionado aos aspectos sociais da produção material da vida, como a distribuição desigual de recursos, a acumulação constante de capital e o desenvolvimento desigual e combinado têm como seu resultado o fato de que "a atual divisão territorial do trabalho, criada a partir de uma tal multiplicidade e diferenciação dos lugares, é desse modo, mais extensa e exigente" (Santos, 1996, p. 219).

Eis que o capital passa a se reproduzir independentemente das realidades que ele irá acionar tecnologicamente. Reproduz-se na dimensionalidade do capital total, tendo como seu mecanismo ativo de reprodução, não o trabalho apropriado no local de uso, mas o meio prático-produtivo que foi introduzido para garantir a incorporação dos trabalhos 
absolutos e relativos, e torná-los partes componentes do sistema técnico de reprodução do capital. O sistema técnico torna-se assim o sujeito da reprodução capitalista ocultando, novamente, o verdadeiro sujeito da exploração do trabalho, agora numa face tecnológica. Em face das particularidades totalitárias dessa sociedade, a noção tradicional de "neutralidade" da tecnologia não mais pode ser sustentada. A tecnologia não pode, como tal, ser isolada do uso que lhe é dado; a sociedade tecnológica é um sistema de dominação que já opera no conceito e na elaboração das técnicas. [...]. Ela antevê maneiras específicas de utilizar o homem e a natureza e rejeita outras maneiras. É um "projeto" de realização entre outros. Mas, assim que o projeto se torna operante nas instituições e relações básicas, tende a tornar-se exclusivo e a determinar o desenvolvimento da sociedade em seu todo. Como um universo tecnológico, a sociedade industrial desenvolvida é um universo político, a fase mais atual da realização de um projeto histórico específico. (MARCUSE, 1967, p. 19)

Ocorre que o desenvolvimento tecnológico não ocorre de forma homogênea no território, posto que está subordinado à lógica geográfica de concentração de capital obedecendo à sua dinâmica de acumulação. Neste sentido, de que adianta o acesso virtual a informações sobre pessoas e lugares dos mais diferentes tipos e origens do mundo, se as condições materiais concretas de comunicação, deslocamento e hoje em dia, até mesmo de reclusão (via quarentena!), permanecem cada vez mais seletivas? Em última instância, a capacidade de controle da circulação de informações, e mesmo de grupos ou mercadorias permanece concentrada nas mãos de determinados grupos, mesmo a despeito da crise econômica e sanitária que hoje se alastra pelo mundo.

Aqui, cabem ainda dois pontos cruciais sobre o uso dessas tecnologias informacionais na educação. O primeiro deles, bem levantado recentemente por Ravitch (2011) no caso estadunidense, a educação elaborada como técnica e, por conseguinte, passível de ser transformada em mercadoria, torna-se objeto não de aprendizagem, mas de recurso a ser apropriado como negócio nas mãos de alguns dos maiores figurões dos EUA ligados à produção de tecnologia como os Koch Brothers, os Waltons (Walmart), Eli Broad, Bill Gates, Michael Bloomberg, Mark Zuckerberg e muitos outros. Deste setor, segundo Ravitch, advém a noção de educação como negócio, seguida de avaliações de desempenho e outros argumentos meritocráticos, acompanhadas de pacotes de ferramentas, softwares e demais plataformas produzidas por estes grupos.

Assim, quem detém os meios de comunicação em massa, os grandes aglomerados de big data? O controle sobre as redes sociais ou os aplicativos baixados nos 
$\overline{\text { computadores, celulares ou notebooks? O que são feitas das informações inseridas }}$ gratuitamente nesses programas? No caso dos professores da rede estadual de ensino do Rio de Janeiro, pressionados de forma contínua a fazerem o uso do Google Classroom, cujos dados não podem ser sequer deletados uma vez inseridos no aplicativo, quem detém a autonomia pedagógica: o docente? O Google? O Estado?

Não à toa, e este é o outro ponto, hoje nos EUA, associações de pais se colocam na linha de frente contra a influência destas corporações na política de educação estadunidense (Ravitch, 2020). Seja para não permitir o acesso destes grandes grupos empresariais aos dados digitais privados de seus filhos, seja para evitar a proliferação dos impactos que a exposição prolongada às telas de computadores, tablets e celulares causa aos jovens como o aumento progressivo de sintomas de insônia e depressão (Freitas, 2018).

\section{Para não esgotar a conversa...}

Por fim, com base nos pontos apresentados acima, gostaríamos de nos posicionar a respeito de duas questões que, a nosso ver, estão mal postas.

O que se observa desde o início da pandemia no Brasil são falas de líderes de governos estaduais e municipais, grupos como o famigerado Todos Pela Educação (TPE) e até mesmo setores do sindicalismo da educação como o Sindicato Estadual dos Profissionais de Educação do Rio de Janeiro (SEPE), que vêm se assentando em duas oposições altamente equivocadas.

A primeira delas se realiza na tentativa de criar uma distinção entre o $\mathrm{EaD}$ e o assim chamado "ensino remoto". De acordo com este argumento, o que se chama de "ensino remoto" é uma prática corrida, improvisada, sem nenhum tipo de planejamento prévio e feita a toque de caixa pelas Secretaria de Educação de estados e municípios com o intuito de atender as demandas imediatas de educação que surgiram em função do fechamento das escolas causado pela pandemia da COVID-19. Em que pese a discussão sobre a suspensão ou não do calendário letivo, a questão toda recai sobre a necessidade da escola ser capaz de oferecer algum tipo de apoio pedagógico aos alunos, uma vez que não é possível a abertura das salas de aula durante a permanência da quarentena ${ }^{7}$.

A recusa de alguns setores em intitular esta prática como característica do $\mathrm{EaD}$ viria do argumento de que esta demanda um conjunto específico de elementos pedagógicos como uma organização curricular prévia, com a elaboração de materiais 
didáticos adequados aos alunos que estarão cursando este tipo de curso, capaz de atender às necessidades educacionais do estudante à distância através da mediação proporcionada pelos materiais e a plataforma virtual.

Aqui nos remetemos ao raciocínio conduzido por Zizek (2003) sobre o funcionamento das ideologias. Neste caso próprio, a ideologia se manifesta sob a forma de uma "pegadinha" toda vez em que é apresentada uma polêmica com forte oposição ou dicotomia imediatamente. Para este autor, este é o momento em que a ideologia aparece em seu caráter mistificador pois, na verdade, o que ocorre é que a verdadeira questão encontra-se ocultada por detrás dessa falsa questão. Da mesma forma, o fato é de que a polêmica "EaD x ensino remoto" não se sustenta, pois a verdadeira pergunta de fundo é: “de que concepção pedagógica estamos falando?”.

O ato pedagógico, para além das mediações simbólicas pelas quais Vigotsky é comumente lembrado, não significa prescindir em momento algum da ação humana direta, ação esta que pressupõe a presença física dos sujeitos. A EaD, neste ponto, não se caracteriza apenas por possuir uma forma específica de organização curricular ou de utilização das mídias digitais de massa. A questão decisiva é a prerrogativa, levantada pelos seus defensores, de que é possível realizar a formação plena do ser humano sem a necessidade da presença física dos sujeitos. Reduzida, a riqueza da experiência pedagógica enquanto prática social se torna mero acesso (ou contato) ao conjunto de conteúdos pré-estabelecidos através da chamada mediação pelas mídias - impressas ou digitais. Estas, por si só, não são capazes de substituir o trabalho pedagógico do professor na sua função primordial de condução do processo ensino-aprendizagem na presença regular dos alunos na escola e na sala de aula. É neste sentido, portanto, que consideramos incabível tentar estabelecer uma distinção real em termos teóricos, entre a $\mathrm{EaD}$ e o ensino remoto, pois o segundo é simplesmente uma versão do primeiro realizada de forma bruta sem o romantismo do primeiro.

$\mathrm{Na}$ atual conjuntura, a crise da acumulação do capital sem precedentes, aliada a terrível crise sanitária que se impôs à toda a sociedade no mundo, aparece como uma espécie de caixa de ressonância onde transparece de forma cruel a que ponto chegamos em termos das terríveis dificuldades que a escola enfrenta já somadas à brutal desigualdade do acesso à educação pública de qualidade. É essa reverberação que deixa explícitas as carências da classe trabalhadora brasileira, mostrando objetivamente quais as dificuldades que alunos, pais e professores enfrentam neste momento, (o acesso a computadores e banda larga de qualidade, a disponibilidade de recursos materiais e 
financeiros que permitam aos pais ficar em casa sem ter de trabalhar e cuidar da educação e da saúde de seus filhos, entre outros...) sendo essas as dificuldades que inviabilizam qualquer possibilidade real de pensar como um pressuposto a formação mediada pelas tecnologias que é a própria EaD. Daí a necessidade de se criar a distinção como tática de defesa dos favoráveis à $\mathrm{EaD}$, uma oposição falsa e mistificadora.

A segunda falsa oposição, destacada recentemente por Freitas (2020), estabelece a crítica à $\mathrm{EaD}$ como uma espécie de resistência da categoria docente ou dos críticos a pensar qualquer tipo de renovação das práticas pedagógicas com o uso das tecnologias da informação (TICs). Nada mais falacioso. Por tudo o que se definiu aqui, fica muito claro que nenhum docente, pai ou mãe de aluno, ou o próprio aluno seria capaz de se colocar como contrário ao uso de qualquer tecnologia. O que se esconde neste caso é a tendência que se avizinha cada vez mais no horizonte pós-pandemia será aquela em que, aproveitando-se desta crise, capital e Estado apresentarão como tábua de salvação nas ruínas do retorno à normalidade o seguinte receituário: o EaD, o homeschooling e, sobretudo, o acesso à educação via vouchers, tal qual nos EUA (Ravitch, 2011, 2020).

Consideramos que a escola deva ser um espaço de investigação da realidade e da construção dos instrumentos necessários ao seu entendimento. O pressuposto é de que o conhecimento é um processo de construção coletiva, resultado não apenas da razão, mas da emoção e da afetividade, em que educador e educando se relacionam como sujeitos do processo de interpretação da realidade. Por isso que a realidade (objetiva e subjetiva), entendida como objeto de estudo, é a mediadora da relação educador-educando. Ambos, partindo dos seus conhecimentos, preconceitos, idiossincrasias, visões do mundo, buscam, por meio da observação, percepção, registro, reflexão, conceituação, síntese, o entendimento realidade que está sempre em processo de transformação.

Nesse caminho, também se coloca a questão da relação entre a teoria e a prática, isto é, do confronto permanente entre a realidade e a consciência, entre o mundo e a percepção do mundo, entre o agir e o pensar, entre a ação e a reflexão, enfim, do movimento da práxis humana.

Por outro lado, a realidade, o seu movimento, é síntese de muitas determinações, ou seja, é síntese de suas várias características, resultado dos seus vários movimentos: cultural, geográfico, econômico, político, natural, histórico, químico, físico, biológico etc. Por isso que a realidade como objeto de estudo é fundamental para um trabalho coletivo da escola, pois permite estabelecer um processo de troca sistemática e de integração das diferentes disciplinas que sobre ela mobilizam os seus instrumentos de investigação. 
Assim, a crítica não é de forma alguma sobre o serviço da tecnologia, mas a quem esta deve servir: aos educadores brasileiros que devem conduzir seu trabalho, e uma escola para a formação intelectual e humana do seu povo, com as ferramentas que estiverem disponíveis. O que a educação brasileira precisa, principalmente após o momento em que essa pandemia cessar, depois de meses de isolamento social, é a presença dos professores e de toda a comunidade escolar nas escolas, não de mais distância na educação.

\section{Notas}

1 - Aqui se compreende que avaliar o rendimento escolar inclui analisar as condições que a escola brasileira oferece ao trabalho pedagógico de professores e estudantes e aos gestores escolares, para alcançar os fins da educação nacional.

2 - Estudantes brasileiros também são inscritos no PISA, embora o Brasil não faça parte da OCDE.

3 - "Corporate reformers". De acordo com Freitas (2012, p. 380), "assim são chamados os reformadores empresariais da educação nos Estados Unidos, em termo criado pela pesquisadora americana Diane Ravitch".

4 - Nos EUA tais punições chegam à demissão de professores e gestores; daí a necessidade de quebrar a estabilidade no emprego.

5 - Persistência, curiosidade, tolerância, resiliência, responsabilidade, gerenciamento de conflitos e cooperação e solução de problemas.

6 - Exemplo curioso dessa inversão deu-se recentemente, numa das lives organizadas pela Associação Nacional de Pesquisa e Pós-Graduação em Educação (ANPEd) sobre EaD. Nesse episódio, no momento que a especialista convidada está comentando sobre as expectativas dos educadores associados à $\mathrm{EaD}$, chega ao ponto de dizer claramente que seu objetivo era "trazer a escola para a internet". Não seria exatamente o contrário: levar a internet para a escola? Não achamos que isto seja um mero ato falho...

7 - Vale a pena aqui destacar o comentário feito pelo Banco Mundial (Banco Mundial, 2020, p.1. Grifo nosso) em documento recente sobre a educação especificamente voltado para o Brasil: Pelo menos três abordagens têm sido adotadas: fechamento total, adotado por 156 países como Peru, França e Malásia; fechamentos parciais, como nos Estados Unidos, onde escolas em zonas de risco foram prioritariamente fechadas 3 , ou na Finlândia onde apenas a educação infantil e anos iniciais são ofertados para as crianças cujos pais estão trabalhando em setores críticos para a sociedade; e, por fim, manutenção das escolas abertas, como a Suécia que alega que os custos do fechamento não superam os ganhos dessa estratégia. Vale destacar que alguns países tomaram medidas progressivas, como em Portugal, que adotou inicialmente fechamento das escolas em áreas de risco, mas optou pelo fechamento total após aumento dos casos e após detectar que a tensão nas escolas prejudicava o aprendizado escolar. O Brasil optou pela alternativa mais conservadora: o fechamento total.

\section{Referências}

BANCO MUNDIAL. Políticas Educacionais na Pandemia do Covid-19: O que o Brasil pode aprender com o resto do mundo? Disponível em: 
https://www.worldbank.org/pt/country/brazil/publication/brazil-education-policy-covid19-coronavirus-pandemic. Publicado em 16/04/2020. Último acesso em 27/04/2020.

FREIRE, P. (1987). Pedagogia do Oprimido. 17ª Edição, Rio de Janeiro: Editora Paz e Terra.

FREITAS, L. C. (2012). Os reformadores empresariais da educação: da desmoralização do magistério à destruição do sistema público de educação. Campinas, SP: Revista Educação e Sociedade, v. 33, nº 119, p. 379-404, abr-jun.

(2020). EAD, tecnologias e finalidades da educação. Disponível em: https://avaliacaoeducacional.com/2020/04/17/ead-tecnologias-e-finalidades-daeducacao/. Publicado em 17/04/2020. Último acesso em 27/04/2020.

(2020). Aprendizagem digital: tempo de tela e depressão.

Disponível em: https://avaliacaoeducacional.com/2018/06/16/aprendizagem-digitaltempo-de-tela-e-depressao/. Publicado em 16/06/2018. Último acesso em 27/04/2020.

HARVEY, D. (1993). A condição pós-moderna - uma pesquisa sobre as origens da mudança cultural. São Paulo: Edições Loyola.

MARCUSE, H. (1967). Ideologia da sociedade industrial. RJ: Zahar Editores.

MARTINS, E. M. (2016). Todos pela educação? Como os empresários estão determinando a política educacional brasileira. São Paulo: Lamparina/FAPESP.

MOREIRA, R. (2016). A geografia do espaço-mundo: conflitos e superação no espaço do capital. Rio de Janeiro: Consequência Ed.

MOTA, G. S. (2016). O PROMETEU TRAídO. Espaço, Técnica e Controle no Capitalismo Monopolista e Tecnológico. Tese (Doutorado em Geografia). Universidade Federal Fluminense. Niterói-RJ.

PINTO, Á. V. (2013). O Conceito de Tecnologia, 2 volumes. Rio de Janeiro: Editora Contraponto

RAVITCH, D. (2011). Vida e morte do grande sistema escolar americano - como os testes padronizados e o modelo de mercado ameaçam a educação. Porto Alegre: Sulina.

(2020).Slaying Goliath: The Passionate Resistance to Privatization and the Fight to Save America's Public Schools. New York: Alfred A. Knopf.

SANTOS, M. (2004). A Natureza do Espaço - Técnica, Tempo, Razão e Emoção. $4^{\text {a }}$. Edição São Paulo: Edusp

SAVIANI, D. (2008). História das ideias pedagógicas no Brasil. Campinas, SP: Autores Associados.

ZIZEK, Slavoj. (2003). Bem vindo ao deserto do real. São Paulo: Editora Boitempo. 